\title{
UMA BREVE ANÁLISE DO "PCK" DE UMA LICENCIADA QUE ATUA NUMA ATIVIDADE COLABORATIVA COM PROFESSOR DA EDUCAÇÃO BÁSICA
}

\section{Leonardo dos Santos Cunha ${ }^{1}$ \\ Luciano Fernandes Silva ${ }^{2}$ \\ Agenor Pina da Silva ${ }^{3}$}

\begin{abstract}
Resumo: Este trabalho propõe uma breve análise do PCK de uma licencianda que participa de uma atividade colaborativa entre universidade e professor de educação básica. Na atividade, ela propõe ideias para a construção de um roteiro experimental para ser aplicado em alunos do ensino médio. Através da análise dos cinco encontros gravados em áudio a qual a ela participa, foram identificadas categorias, utilizando o modelo de PCK de Park e Oliver (2008), mais presentes que caracterizam seu PCK. Enfim, como resultado, a licencianda apresenta conhecimentos de conteúdo, currículo e instrucionais bem evidentes, enquanto sua capacidade de trabalhar com alunos e pensar na atividade considerando as dificuldades dos alunos não são tão desenvolvidas.
\end{abstract}

Palavras-chave: PCK; Atividade colaborativa; Educação básica; Ensino de Ciências.

\footnotetext{
1 Universidade Federal de Itajubá, Brasil. E-mail: leonardodosscunha@yahoo.com.br.

2 Universidade Federal de Itajubá, Brasil. E-mail: lufesilva@unifei.edu.br.

3 Universidade Federal de Itajubá, Brasil. E-mail: agenor@unifei.edu.br.
} 